\title{
Social work practice with Arab Muslim women living in Western societies
}

\section{Bassima Schbley $^{1}$ and Mark Kaufman ${ }^{2}$}

Summary: This article discusses how practice teachers and others involved in social work education can enhance the quality of services being provided to Arab Muslim women living in Western societies. It draws upon the relevant literature, as well as the results of a small-scale survey by the lead author of Arab Muslim women living in the United States. The authors argue that social work learning cannot be separated from the influence of culture, which sometimes includes religious beliefs and practices.

Keywords: cultural competence; Arab Muslim women; social work practice

1. Assistant Professor, Dept of Social Work, Washburn University, Topeka, Kansas

2. Associate Professor, Dept of Social Work, Washburn University, Topeka, Kansas

Address for Correspondence: Bassima Schbley, Dept of Social Work, Washburn University, 1700 College Avenue, Topeka, KS 66621, USA. bassima. schbley@washburn.edu 


\section{Introduction}

During the past 15 years, there has been an increasing recognition within social work and the other social service professions in Europe and North America that 'more emphasis should be placed on training students for cultural competence during their field work' (Kaufman and Love, 2003, p.30). This period has seen an increase in the academic literature devoted to this topic in Great Britain (e.g. Humphries, 1998), France (e.g. Ion and Ravon, 2001), the United States (e.g. Lum, 2000), and many other countries as well (e.g. Healy, 2001). The value of this literature has been recognized, both in general terms (Corey, Corey and Callanan, 2003) and in its specific contribution to advances in areas such as anti-oppressive practice (Issitt, 1999). However, this growing literature has also been criticized for not sufficiently providing practice teachers and classroom teachers with 'down-to-earth practical ideas which are readily adaptable to students' needs and abilities' (Ronnau, 1994, pp.30-31). For example, one practice learning coordinator in Great Britain questioned 'whether practice teachers and others in social work education are giving sufficient attention to assisting students to explore the potential significance of religion to ... the lives and perspectives of service users' (Gilligan, 2003, p.75).

This lack of attention to the significance of religion in the lives of some service users is a matter of concern, given the complex and contrasting trends toward both secularism and religiosity in the countries of Western Europe and North America. Furness (2003) observed that 'Britain has witnessed over the past forty years declining numbers of people who attend [Christian] church ... in contrast to Pakistani and Bangladeshi Muslims who still place religion central to their lives' (p.62). Consequently, 'social work in Britain takes place in a diverse society made up of people ranging from those for whom religious beliefs and traditions determine and dominate their whole way of life ... to those who would say that it had little or no influence on their actions and behaviors' (p.62). Gilligan (2003) similarly noted that 'in Britain ... for a large and increasing number of service users, religion is a basic aspect of human experience, both within and outside the context of religious institutions' (p.77). Despite this fact, Gilligan's recent survey research 'tends to reinforce the earlier impression that social work has not, and is not, giving issues of religion and belief priority in the education and training of social workers' (p.80). He argues that 'practice teachers need

26 Journal of Practice Teaching \& Learning 7 (2) 2006-07, pp.25-38. @ 2007 Whiting \& Birch Ltd 
to urgently review their practice with regard to the exploration of issues concerning religion and belief with students, if they are to become competent social workers' (p.75).

Our article is a response to this increasing recognition that more emphasis should be placed on training students for cultural competence in their field work, including competence in understanding the impact of religious beliefs and practices on the lives of clients. We focus on the social service needs of Arab Muslim women who were born and raised in the Middle East, but who are now living in Western societies. We focus on this client population for four reasons. First, developing the knowledge and confidence to effectively provide services to any culturally diverse group is a skill set that should generalize, to some degree, to all minority clients. Second, developing these skills vis-à-vis Arab Muslim women should particularly generalize to more effective service delivery to other Muslim clients (non-Arabs, and men), a growing segment of minority clients in Western societies. Third, the service needs of Arab Muslim women often are particularly challenging, given the frequently difficult transition from growing up in a very 'traditional' religious culture and then relocating to a largely secular Western society. Fourth, the lead author of this article was raised as an Arab Muslim woman in Lebanon until age 16, has lived for many years in the United States, and has a long-standing interest in the topics explored in this article. This interest was spurred further by a review of two recent research studies (both supported, at least in part, by the United Nations) that examined the increasingly challenging problems faced by Arab Muslim women in an era of religious fundamentalism in their countries of origin. The current article will discuss the results of the lead author's recent survey research with 15 Arab Muslim women who relocated to the United States from Lebanon. The details of this research both confirm and elaborate upon the United Nations-sponsored studies, which will also be examined.

This article consists of three sections. First, we briefly summarize some of the recent academic literature on multicultural social work practice, emphasizing the elements of that literature that are most relevant to this article. Second, we present the lead author's recent original research findings, the results of the 15 in-depth interviews referred to above. Third, we discuss some of the specific implications of this research for practice teaching and social work education. 


\section{Multicultural social work literature and religion}

Noting the relatively small amount of published material on either religious beliefs or spirituality that is specifically aimed at social workers, Gilligan (2003) observed that 'to talk about religion and spirituality is for many people as embarrassing as talking about sex, death and money' (p.78). Despite this, he argues that, for clients seeking social services, these are issues that sometimes need to be talked about, and with sensitivity and competence. In fact, as Crompton (1998) reminded us, the Children Act of 1989 in Great Britain highlighted the law's expectation that social workers will give explicit attention to the religious needs of young clients, when appropriate.

Of course, it is not always easy to determine when such attention is appropriate. On the one hand, Patel, Naik, and Humphries (1998) emphasized that 'religious cultural practices' and 'religion as therapy' have 'no place in social work education and practice' (p.ii). Instead, these authors advocated for a more informed understanding of religious differences and for social work students to become better prepared to practice in a pluralistic society. On the other hand, while fully recognizing that social work must protect its boundaries and remain a wholly secular profession, Derezotes (1995) observed that the religious and spiritual values of clients will sometimes influence the assessment and intervention strategies developed by social workers. Attempting to find the right balance, Gilligan (2003) observed; 'There is clearly an ... unresolved confusion amongst many social workers and social work educators about what role discussion of religion and belief can play, in an apparently "modern" and "secular" age, and more especially in the context of a commitment to anti-oppressive practice' (p.76).

Some efforts to address this confusion have been productive. For example, Furness (2003) conducted a small-scale survey with social work students in Bradford, England, to elicit their views about the impact of faith and belief on social work practice. Focusing on the significant Muslim population in Bradford, Furness warned against the 'misconception that all Muslims and Asians are a homogeneous group and that they share very similar traditions and customs' (p.63). The author described a picture of 'commonalities, differences, and [the] separate nature of these diverse communities' (p.63). These are themes to which we will return in the next section of our article.

28 Journal of Practice Teaching E Learning 7(2) 2006-07, pp.25-38. () 2007 Whiting \& Birch Ltd 
Other studies have sought to introduce some clarity to this challenging topic by developing cohesive frameworks to guide multicultural social work practice. For example, Kaufman and Love (2003), in an extensive review of the British and North American social work literature on multicultural practice, concluded that three themes frequently recur. First, many studies stress the importance of the practitioner's awareness of his or her own cultural values and biases. Second, it is vital to recognize that a culturally competent practitioner seeks to understand the worldview and culture of the client, and possesses at least some specific knowledge of diverse client groups and of relevant sociopolitical influences. Third, the effective practitioner should possess specific skills and intervention techniques to serve culturally diverse clients. We will return to these three themes later in this article.

Next, however, we examine recent research that should help practitioners better understand the service needs of Arab Muslim women now living in Western societies. We are not the first to examine the service needs of a particular group. For example, the British social work literature has examined the specific psychosocial needs of racial minorities (Kirton, 1999), and the academic literature has helped social workers in Spain to work more effectively with immigrants to that country (Pacheco, Plaza, Fernandez-Ramirez and Andres, 2003). There is an extensive social work literature in the United States focusing on the specific needs of Spanish-speaking immigrants (Beckett and Dungee-Anderson, 1996).

\section{Research results: Arab Muslim women in Western societies}

An impetus for our own survey research on this topic, conducted in 2003, has been the Human Development Report issued intermittently (in 1985, 1988, 1992, 1994, 1996, and 2000) by the United Nations Development Program (2000). Over the past two decades these authoritative reports have utilized 62 socioeconomic, medical, and political 'indicators' to conduct cross-cultural analyses of the world's developing countries. These reports present a stark picture of the declining status and well-being of Arab Muslim women in Lebanon. These women are being forced back into the confinement of their

29 Journal of Practice Teaching \& Learning 7(2) 2006-07, pp.25-38. @ 2007 Whiting \& Birch Ltd 
families and away from opportunities in the public sphere of community and national affairs that Lebanon's past had provided (see also Shehadeh, 1998). The reason for these changes certainly appears to have been the dramatic resurgence of religious fundamentalism over the past 20 years among large segments of the Lebanese Muslim population (Joseph, 1994). The effects of this resurgence are reflected in the U.N. Human Development Report of 2000. According to this report, less than 45\% of Muslim Lebanese women were employed outside the home; that figure had been $60 \%$ in 1980. In 2000, the average salary of Muslim Lebanese men was 85\% higher than that of Muslim Lebanese women; this percentage had been $47 \%$ in 1980 .

To suggest that some versions of religious fundamentalism may pose challenges to some of the typical social development goals encouraged by the social work profession is not meant to suggest that these religious affiliations fail to meet other human needs. We certainly do not wish to imply that anyone should be prohibited from any type of religious affiliation. Nor are we suggesting that Islamic religious fundamentalism is unique among religions in raising concerns related to social development goals. Social work values require that all such issues be addressed with tolerance and respect. We stress that the issues discussed in this article are simply examples of the challenges that confront social workers in pluralistic Western societies when working with clients who were raised in very traditional religious societies.

The lead author solicited participation in a qualitatively oriented interview process from Muslim Lebanese-born adult women who had lived in Lebanon at least until 1995, and who were currently residing in Wichita, Kansas (a Midwestern U.S. city with a population of approximately 370,000 ). Participation was sought from 15 such women from various socioeconomic backgrounds for in-depth interviews focusing on many aspects of their life experience both in Lebanon and in the United States. One-page flyers that explained the purpose of the study and that solicited volunteers were posted at the local Wichita Muslim Community Center. To reduce any 'cohort effect' (related to age and socioeconomic status), basic demographic information was collected from each of the initial respondents to the flyers. Fifteen volunteers were then selected from among all of the respondents, with an effort to reduce any cohort effect. Nonetheless, the participants obviously did 'self-select' by volunteering initially, and the interviewees cannot be viewed as a fully random sample of all Muslim Lebanese women living

30 Journal of Practice Teaching \& Learning 7(2) 2006-07, pp.25-38. ๑ 2007 Whiting \& Birch Ltd 
in Wichita, Kansas (or in the United States, of course).

The 15 participants ranged in age from 19 to 69, and all were currently married (except for the 69-year-old participant, who was divorced). There was a significant degree of socioeconomic diversity. Three of the women were very poor and were receiving poverty-related public welfare benefits. Two women were employed and viewed their job as supplementing their husband's income. Three women owned their own businesses. Five women were married to engineering or medical professionals and two women were financially supported by their adult children. The effort to recruit women from various Islamic religious sects was also successful: nine women were affiliated with the Sunni Abbassy sect, three with the Shia Jafary sect, two with the Suni Hanafy sect, and one with the Shia Twelvers sect. This pattern was expected because these are the most common Islamic sects both in Lebanon and in Wichita, Kansas.

The qualitative design for these open-ended interviews was guided by a dual emphasis on 'narrative-interpretive theory' (Marshall and Rossman, 1999) and the 'feminist critical theory paradigm' (Fine, 1992; Rubin and Babbie, 2001; Stewart, 2001). Feminist critical theory focuses on the interplay of power between genders and also seeks to be sensitive to the potential interplay of power between researcher and research participant. This focus seemed of particular importance to the lead author because she was once an 'insider' (born in Lebanon and lived there until age 16) who is now more of an 'outsider.' All interviews were conducted in Arabic, the primary language of all the participants. However, many of the participants' thoughts and expressions were uttered in English. All interviews were audiotaped. Fully informed consent was obtained from each participant, which permits utilization of all data, although without any reference to the names of participants or significantly identifying descriptions. The audiotaping was used only for documentation, translation, and interpretation of the data. The lead author subsequently listened to each audiotape and translated each one from oral Lebanese Arabic into written English. After each interview, the lead author recorded her personal reflections in a journal in an effort to monitor her own reactions to the interview, to identify possible biases, and to reflect on how she might alleviate any such biased questioning during subsequent interviews.

Each transcript was reviewed several times in order to identify common themes, which were then labeled as such (Morrow and Smith, 2000).

31 Journal of Practice Teaching \& Learning 7(2) 2006-07, pp.25-38. (C 2007 Whiting \& Birch Ltd 
Seventeen common themes were identified and grouped in three broad categories: (1) the role of the interviewees as Lebanese Muslim women, wives, and citizens; (2) a discussion of their education, employment, and overall life satisfaction; and (3) the impact of religion on their lives. Because our findings are quite similar to those of an impressive and influential wide-scale research project that recounts similar narratives of Arab Muslim women from Egypt, Jordan, Tunisia, Yemen, and the Palestinian Territories (Jabre, Underwood and Goodsmith, 1997), we discuss the findings from our study and the other study together (noting the study to which we are referring). Jabre et al's (1997) research was an advocacy and training project intended to promote and document women's empowerment and active participation in social development in the Arab world. It was 'carried out with support from the United States Agency for International Development, the European Commission, and the Arab Gulf Programme for United Nations Development Organizations' (Jabre, Underwood and Goodsmith, 1997, p.iii).

Each of the 15 women in our study and each of the 30 women profiled in the study by Jabre et al appear to view their achievements and their struggles within the broader context of their families and communities. This was the most remarkably consistent theme within and between the studies. Jabre et al observed:

In Arab culture, the individual is more deeply embedded in a closely connected social network than in most Western contexts, and becomes actualized by being part of, and working for, the well-being of the group. Rather than being measured by Western standards of personal success and individual gratification, achievement is recognized chiefly through contributions made within this familial and social context. (p.93)

Similarly, Jacobson (1994) observed that:

Western notions of autonomy based on the concepts of privacy and individual rights ... may be less relevant to Muslim women, who value the interdependence of individuals, families, and communities. (p.26)

We discuss additional findings of our own survey research in the following section of our article, which focuses on various implications for practice teaching and social work education. 


\section{Implications for practice teaching and social work education}

Several findings from our study have significant implications for practice teaching and social work education. One of the most significant findings was that few of the participants in our study seemed willing to jeopardize their marriages or compromise their roles as mothers and daughters by harshly criticizing their social and religious milieu, despite referring to various inequities. For example, some participants noted that Islam mandates that a Muslim woman must submit to the will of her husband or father, as long as these men do not contradict Islamic law ('Sharia'). Participants in our study reported numerous incidents in Lebanon in which female friends and family members were either divorced or fired from jobs for defying religious prohibitions, or for nonconformance with dress codes. Others were punished merely for using perfume. Many had been prohibited from higher education, restricted from driving automobiles, and forced into marriage. Our participants and those in the study by Jabre, Underwood and Goodsmith frequently described their need to focus on resolving the tensions between their personal needs and their perceived family responsibilities.

The result of these tensions, as Jabre and colleagues (1997) insightfully observed, is a 'complex blending of respect for, and resistance to, established traditions' (p.93). Most of the women in our study referred both to a stronger religious affiliation and to greater life satisfaction since moving to the United States. Clearly they also appreciated the increased economic opportunities. They tended to explain their higher levels of overt religiosity while living in Wichita, Kansas, as in part a reaction to perceived hostility toward Islam by many in the United States, particularly since September 11, 2001. Some felt the need to affirm their Islamic heritage by wearing a veil. At the same time, however, many of these women expressed an ongoing concern about the resurgence of religious fundamentalism in Lebanon.

Another significant finding of our study with major implications for practice teaching and social work education is that most of the participants in our study had already stepped outside traditional roles and found new opportunities, including employment, community volunteer work, and social and political activism. Most of the participants in our study had vigorously pursued these new opportunities in the United

33 Journal of Practice Teaching \& Learning 7(2) 2006-07, pp.25-38. (C 2007 Whiting \& Birch Ltd 
States, and some had begun this effort while still living in Lebanon. This was again also true for the majority of the participants in the study by Jabre, et al.

What factors had encouraged these women to pursue such opportunities? Many of the women mentioned receiving emotional support from family members, particularly husbands and fathers. Given traditional expectations about female roles, there were some inevitable tensions when these women became involved in matters outside the home. To avoid these problems, some women chose to marry men who supported their personal goals and outside involvements. When tensions did arise, most of the women in both studies turned to the arts of persuasion and negotiation. Rather than directly challenging their husband's position as head of the family, they sought to maintain family harmony. They pursued a 'gradualist' strategy to eventually obtain the support of their husbands. Social workers who develop a familiarity with and sensitivity toward the typical relationship patterns of Arab Muslim families may sometimes be in a position to facilitate such productive negotiations.

In their efforts to pursue personal goals, many of the women in these two studies also received emotional and practical support from friends and neighbours. Such informal social networks are not constrained by rigid hierarchies and can be quite facilitating. Again, the sensitive and well-trained social worker may be in a position to make a positive contribution to this process. As Jabre, Underwood and Goodsmith (1997) observed:

Bringing women who have led relatively isolated lives into a group with a clearly defined purpose - such as a literacy class or a small business loan program - begins a process that neither the individual nor the group's sponsor may have foreseen... [T] he accomplishments of each woman in a group serve as an inspirational and practical model for others to emulate. (p.104)

We conclude this section with specific suggestions about how our research findings can be usefully applied by practice teachers and other social work educators. In linking our findings to the practice teaching and learning process, we refer again to the various dimensions of effective multicultural social work practice discussed by Kaufman and Love (2003). They argue that there is value in teaching students about

34 Journal of Practice Teaching \& Learning 7(2) 2006-07, pp.25-38. @ 2007 Whiting \& Birch Ltd 
specific strategies, skills, and interventions that seem appropriate for specific minority clients, and helping students to become more aware of the impact of their own cultural values, and more aware of the worldview and culture of their clients.

Practice teachers and educators should strive to create an atmosphere in which cultural differences can be explored and questions asked. We have described the very different family culture and political atmosphere in which many Arab Muslim women clients have been raised. It is not reasonable to expect most social work students to be fully conversant about such issues. However, the practice teacher should help the student to identify the kind of information that is required to understand what is going on in the helping situation. Following Pinderhughes (1989), we encourage practice teachers to seek exploration of the following issues when their students are working with Arab Muslim women who were raised in the Middle East:

1. To what extent is the presenting problem related to issues of transition, such as immigration?

2. Is the behavior at issue considered normal within the client's own culture, or is it considered dysfunctional?

3. To what extent is the current problem a manifestation of lack of access to resources and environmental supports?

4. To what extent is the problem related to culture conflict in identity, values, or relationships?

5. Is the client a participant in any Muslim organizations that have been particularly helpful?

6. What are the other available cultural strengths and resources, such as cultural practices, social networks, and family support systems?

Regarding the sixth point, practice teachers should encourage their students to actively seek out opportunities in the community to learn about Arab and Muslim culture, because our research findings (and other research as well) point to some significant differences from Western cultures. In many communities, a wide variety of cultural events occur throughout the year, and many of them will be available at minimal or no cost to students. If the practice teacher periodically informs students about these events, it 'serves as a reminder that cultural awareness is valued, is an ongoing process, and requires active involvement' (Ronnau, 1994, p.35). Students also should be encouraged to listen to music

35 Journal of Practice Teaching \& Learning 7(2) 2006-07, pp.25-38. @ 2007 Whiting \& Birch Ltd 
and read books and poetry by Muslim Arabs. Students might usefully visit other agencies that specifically serve Arab Muslim clients, such as refugee programs, women's centers, advocacy groups, and community centers.

Finally, our research findings demonstrate the importance that Arab Muslim women place on their connection to extended helping networks within their own communities. Therefore, practice teachers and classroom teachers should consider inviting respected members of that community to meet with students in order to explain how cultural and religious factors might influence how clients perceive the social agency's programs and services. Such diversity training workshops can make use of the skills of community leaders who will be found in many cities. In a similar vein, our research suggests that practice teachers should encourage their students to make the fullest possible use of appropriate indigenous sources of helping within the client's own community. Social services usually are enhanced when practitioners have learned how to incorporate naturally occurring support systems. This includes the extended family system, as well as the broader religious community. At times, it may be appropriate to seek consultation with religious leaders in the community.

\section{Conclusion}

Jabre, Underwood and Goodsmith (1997) concluded their study with a set of recommendations for social service professionals who seek to enhance the personal and social development goals of Arab Muslim women. These recommendations include the following: (1) offer access to new ideas, information, and resources; (2) foster social support for women's education and their active participation in public life; and (3) help women better understand their legal rights and how to obtain them (pp.117-118). These appear to be thoughtful, appropriate recommendations, assuming that they are pursued with tact and sensitivity, and with a recognition of the family dynamics that may create challenges for such a pursuit.

Ahmad (1996) reminds us that 'cultural norms provide guidelines for understanding and action, guidelines which are flexible and changing, open to different interpretations across people and across

36 Journal of Practice Teaching \& Learning 7 (2) 2006-07, pp.25-38. @ 2007 Whiting \& Birch Ltd 
time, structured by gender, class, and other contexts' (p.190). We also concur with Gilligan's (2003) reminder that 'for practice teachers and for social work students ... learning cannot be separated from the influence of context and culture, including religion and belief' (p.85). We encourage practice teachers and other educators to proceed with a commitment to social justice, and with the confidence that their efforts will contribute to increased social cohesion in our rapidly integrating world community.

\section{References}

Ahmad, W. (1996) The trouble with culture, in D. Kelleher and S. Hillier (Eds.) Researching Cultural Differences in Health . London: Routledge (pp.190-219)

Beckett, J.O. and Dungee-Anderson, D. (1996) A framework for agency-based multicultural training and supervision. Journal of Multicultural Social Work, 4, 4, 27-48

Corey, G., Corey, M.S., and Callanan, P. (2003) Issues and Ethics in the Helping Professions. Pacific Grove, CA: Wadsworth

Crompton, M. (1998) Children, Spirituality, Religion and Social Work. Aldershot: Ashgate

Derezotes, D.S. (1995) Spirituality and religiosity: Neglected factors in social work practice. Arete, 20, 1, 1-15

Fine, M. (1992) Disruptive Voices: the Possibilities of Feminist Research. Ann Arbor, MI: University of Michigan Press

Furness, S. (2003) Religion, beliefs and culturally competent social work practice. Journal of Practice Teaching, 5, 1, 61-74

Gilligan, P. (2003) 'It isn't discussed.' Religion, belief and practice teaching: Missing components of cultural competence in social work education. Journal of Practice Teaching, 5, 1, 75-95

Healy, L.M. (2001) International Social Work: Professional action in an interdependent world. New York: Oxford University Press

Humphries, B. (1998) Contemporary practice learning in social work: Tensions and possibilities. Journal of Practice Teaching, 1, 2, 4-12

Ion, J. and Ravon, B. (2001) Les Travailleurs sociaux. Paris: La Decouverte

Issitt, M. (1999) Towards the development of anti-oppressive practice: the challenge for multi-disciplinary working. Journal of Practice Teaching, 2, 2 , 21-36

37 Journal of Practice Teaching \& Learning 7(2) 2006-07, pp.25-38. @ 2007 Whiting \& Birch Ltd 
Jabre, B., Underwood, C., and Goodsmith, L. (1997) Arab Women Speak Out: Profiles in self-empowerment. Baltimore, MD: Johns Hopkins University School of Public Health

Jacobson, J. (1994) Family, Gender, and Population Policy: Views from the Middle East. New York: The Population Council

Joseph, S. (1994) Problematizing gender and relational rights: Experiences from Lebanon. Social Politics, 1, 3, 271-285

Kaufman, M. and Love, D. (2003) Recent trends in multicultural practice: Implications for practice teaching and field education. Journal of Practice Teaching, 4, 3, 29-53

Kirton, D. (1999) Perspectives on race and adoption: The views of student social workers. British Journal of Social Work, 29, 779-796

Lum, D. (2000) Social Work Practice and People of Color. Belmont, California: Brooks/Cole

Marshall, C. and Rossman, G. (1999) Designing Qualitative Research. Thousand Oaks, California: Sage Publications

Morrow, S. and Smith, M. (2000) Qualitative research for counseling psychology, in S.D. Brown and R.W. Lent (Eds.) Handbook of Counseling Psychology. New York: Wiley (pp.199-230)

Pacheco, E.R., Plaza, S.H., Fernandez-Ramirez, B., and Andres, P.C. (2003) The implications of immigration for the training of social work professionals in Spain. British Journal of Social Work, 33, 49-65

Patel, N., Naik, D., and Humphries, B. (Eds.). (1998) Visions of Reality, Religion and Ethnicity in Social Work. London: CCETSW

Pinderhughes, E. (1989). Understanding Race, Ethnicity, and Power. New York: The Free Press

Ronnau, J.P. (1994) Teaching cultural competence: Practical ideas for social work educators. Journal of Multicultural Social Work, 3, 1, 29-42

Rubin, A. and Babbie, E. (2001) Research Methods for Social Work. Belmont, CA: Brooks-Cole

Shehadeh, L. (1998) The legal status of married women in Lebanon. International Journal for Middle Eastern Studies, 30, 501-519

Stewart, A. (2001) Theorizing Feminism: Parallel trends in the humanities and social sciences. Boulder, CO: Westview Press

United Nations Development Program. (2000) Human Development Report. Retrieved May 24, 2002, from http://www.undp.org.1b/ 